\title{
«Decir con el arte que este dice» Hernando de Acuña, traductor de Ovidio
}

\author{
«Decir con el arte que este dice» \\ Hernando de Acuña, translator of Ovid
}

\author{
Antonio Río Torres-Murciano \\ Universidad Nacional Autónoma de México
}

\begin{abstract}
RESUMEN: En La contienda de Áyax Telamonio y de Ulises sobre las armas de Aquiles, Hernando de Acuña ha vertido con notable fidelidad un pasaje de las Metamorfosis de Ovidio (XII 622-XIII 394). De este modo, ha puesto en práctica su propia teoría de la traducción, tal como él mismo la plantea a propósito de Le chevalier délibéré.
\end{abstract}

Palabras clave: Hernando de Acuña, Ovidio, traducción.

ABSTRACT: In his poem La contienda de Áyax Telamonio y de Ulises sobre las armas de Aquiles, Hernando de Acuña has made an accurate translation of a passage from Ovid's Metamorphoses (XII 622-XIII 394). In this way, he has put into practice his own translation theory, as it is put forward with regard to Le chevalier délibéré.

Keywords: Hernando de Acuña, Ovid, translation.

En consonancia con el subtítulo, el presente estudio se propone examinar la labor de Hernando de Acuña como traductor, propiamente dicho, de Ovidio, y no como recreador o adaptador de temas y pasajes ovidianos. Caen, pues, fuera de nuestro campo de atención aquellos sonetos de las Varias poesías ${ }^{1}$ en que

\footnotetext{
${ }^{1}$ Varias poesías compuestas por don Hernando de Acuña, Madrid, en casa de P. Madrigal, 1591 (BNE R 2738). Se citará el texto por la edición prínceps, modernizando la ortografía y la puntuación; en la Biblioteca Virtual Miguel de Cervantes puede consultarse el facsímil digital $<$ http://www.cervantesvirtual.com/FichaObra.html?Ref=13545>. [Consulta: 5 sept. 2008]. Hemos tenido en cuenta, asimismo, la edición de L. F. Díaz Larios, Hernando de Acuña. Varias poesías, Madrid, Cátedra, 1982.
} 
don Hernando se limita a construir una narración condensada de episodios míticos que habían hallado extenso desarrollo en la obra del Sulmonense, como son los de Hero y Leandro (fol. 144r), Ícaro (154r) y Faetón $(154 \mathrm{v})^{2}$. Tampoco nos ocuparemos detenidamente de la La fábula de Narciso (1r-16v), que, a pesar de los añadidos ovidianos y demás innovaciones introducidas por Acuña ${ }^{3}$, es en su mayor parte versión del poema homónimo de Luigi Alamanni ${ }^{4}$. Nuestro principal objeto de análisis lo constituirá La contienda de Áyax Telamonio y de Ulises sobre las armas de Aquiles (36v-54v), poema que, junto con la Carta de Dido a Eneas $(79 \mathrm{v}-85 \mathrm{r})^{5}$, demuestra la habilidad con que nuestro autor ha sabido poner el latín de Ovidio en verso castellano.

La Contienda de Acuña reescribe en 887 endecasílabos sueltos los 415 hexámetros del pasaje ovidiano que, a caballo entre los libros XII y XIII de las Metamorfosis, narra la disputa entre Áyax, el bravo hijo de Telamón, y Ulises, elocuente rey de Ítaca, por las prodigiosas armas que había cincelado Vulcano para el difunto Aquiles, pleito que, tras haber oído a ambas partes, fallan a favor del Ítaco los capitanes griegos que participan en el asedio de Troya ${ }^{6}$. El asunto, aludido ya en el canto XI de la Odisea (vv. 543-565), había gozado de gran predicamento entre los autores antiguos ${ }^{7}$, pero es Ovidio quien lo transmite a la posteridad medieval y renacentista mediante su personal versión del armorum iudicium, que don Hernando sigue muy de cerca. El poeta español plantea primeramente el conflicto mediante una introducción que, si en parte es original (vv. 1-21), concluye transcribiendo los vv. 622-628 del libro XII de las Metamorfosis (vv. 22-37); a partir del v. 38, sigue el libro XIII desde el v. 1 hasta la cesura pentemímera del v. 394 (expulit ipse cruor $^{8}$, traducido en el v. 884: «y bastó sólo el golpe de la sangre»), y sustituye finalmente los vv. 394b-

\footnotetext{
${ }^{2}$ Cfr. respectivamente Ovidio, Heroidas, XXVIII y XIX; Metamorfosis, VIII 183 y sigs.; II 1 $\mathrm{y}$ sigs.

${ }^{3}$ Los vv. 97-120 son versión amplificada de Ovidio, Metamorfosis, III 341-350.

${ }^{4}$ Publicado en Opere toscane, Venecia, Herederos de Lucas Antonio Giunta, 1542.

5 Acerca de la atribución a Acuña de esta epístola, cfr. Díaz Larios, cit., pág. 215 n.

${ }^{6}$ Cfr. J. P. W. Crawford, «Notes on the Poetry of Hernando de Acuña», Romanic Review, 7, 1916, págs. 314-327 [324]; M. Menéndez Pelayo, Biblioteca de Traductores Españoles, I, Santander, Aldus / CSIC, 1952, págs. 28-32 [31]; R. Mateo Mateo, «Sobre el tema de las armas y las letras en la poesía narrativa de Hernando de Acuña», Castilla, 6-7, 1983-1984, págs. 73-100 [74]; M. Rubio Árquez, «La contienda de Áyax Telamonio y de Ulises sobre las armas de Aquiles de Hernando de Acuña: fuentes, motivos y significación», La espada y la pluma. Il mondo militare nella Lombardia spagnola cinquecentesca. Atti del Convegno Internazionale di Pavia, 16, 17, 18 ottobre 1997, Viareggio, Mauro Baroni, 2000, págs. 385-406 [387 y sigs.].

${ }^{7}$ Cfr. F. Bömer, P. Ovidius Naso, Metamorphosen. Buch XII-XIII, Heidelberg, Carl WinterUniversitätsverlag, 1982, págs. 196-197.

${ }^{8}$ El texto ovidiano que seguiremos es el de W. S. Anderson, P. Ovidii Nasonis Metamorphoses, Leipzig, Teubner, 1982.
} 
398 del texto latino, que ponían la coda al suicidio de Áyax narrando el nacimiento de la flor del jacinto a partir de su sangre derramada en tierra, por lo que podríamos denominar una «visión racionalizada» del mito (vv. 885-886) ${ }^{9}$. A pesar de estas alteraciones, y de otras menores que tendremos ocasión de comentar, la fidelidad con que refleja la Contienda el texto de las Metamorfosis es tal que, a nuestro juicio, sólo la confrontación con el modelo latino puede darnos una idea cabal de las intenciones y méritos de la versión castellana.

En su estudio acerca de la Contienda, Marcial Rubio Árquez sostiene que Acuña se desembaraza de la visión peyorativa de Ulises heredada del Medioevo y presente todavía en obras como los Emblemas de Alciato (XXXVIII y XLVIII), los sonetos de Hurtado de Mendoza (XXXIII y XXXIV) y Las lágrimas de Angélica de Barahona de Soto (canto VII, estrofas 32 y 33), y que lo hace para proponer un concepto actual del hombre de armas basado en la benigna opinión que, siguiendo a Homero, se habría forjado Ovidio con respecto al héroe de Ítaca, «perfecta conjunción del guerrero y del sabio» ${ }^{10}$. No estamos, empero, seguros de que el reconocimiento de los méritos de Ulises fuera en Ovidio tan inequívoco como este autor da por sentado. La idea de que el poeta romano toma decididamente partido por Ulises frente a Áyax ha hallado su más resuelto valedor en L. P. Wilkinson ${ }^{11}$, que consideraba que, al preferir a Ulises, Ovidio estaba reaccionando contra toda una tradición literaria hostil al de Ítaca, a quien Píndaro y los trágicos habían convertido de héroe en villano a pesar de la discreta simpatía que le había dispensado Homero. Más cautela ha mostrado Franz Bömer al relativizar esta interpretación en su monumental comentario a las $\mathrm{Me}$ tamorfosis $^{12}$. Señala el erudito alemán que, si bien es cierto que Ovidio trata en general a Ulises con benevolencia, no lo es menos que concede al Telamonio su parte de razón, haciendo del viejo héroe mudo de Píndaro ${ }^{13}$ un digno rival para la taimada oratoria del de Ítaca, un Áyax locuaz y desenvuelto cuyas habilidades persuasivas lo sitúan muy por encima del obtuso guerrero o dull-witted soldier que Wilkinson quiso ver en é ${ }^{14}$. En opinión de Bömer, la cuestión acerca de la preferencia del autor por alguno de sus personajes ni siquiera es pertinente, toda vez que, a la hora de oponer los argumentos de uno y de otro, Ovidio adopta una actitud más bien distante, propia del tratamiento escolástico dado al

\footnotetext{
9 «la cual, saliendo en abundante vena, / volvió la verde yerba en colorada, / quedando al derredor tinta la tierra.»

${ }^{10}$ Cit., pág. 398. Cfr. Díaz Larios, cit., pág. 48.

${ }^{11}$ Ovid Recalled, Cambridge, Cambridge University Press, 1955, págs. 229-230. Cfr. B. Otis, Ovid as an Epic Poet, Cambridge, Cambridge University Press, 1966, págs. 283-285.

12 Cit., págs. 198-200.

${ }^{13}$ Cfr. Nemeas, VIII 24.

${ }^{14}$ Cfr. W. B. Stanford, The Ulysses Theme. A Study in the Adaptability of a Traditional Hero, Oxford, Basil Blackwell, 1954, pág. 139.
} 
armorum iudicium por los sofistas griegos y por los cultivadores romanos de la retórica. Desde esta perspectiva, el episodio ovidiano se descubre como lo que a nuestro juicio en verdad es: un claro ejemplo de aplicación del arte de la controversia a la composición literaria, donde el Sulmonense se permite hacer gala de virtuosismo al confrontar las orationes del hombre de acción y del hombre de ingenio sin pronunciarse claramente a favor de Áyax o de Ulises ${ }^{15}$.

No creemos, pues, que Ovidio se hubiera propuesto rehabilitar a Ulises. Tampoco que Acuña se haya decantado por este en detrimento de Áyax ${ }^{16}$, privilegiando los argumentos y el modo de expresión del primero sobre los del segundo ${ }^{17}$. El discurso del Telamonio no sólo no resulta en el poema castellano «torpe y enfadoso» ${ }^{18}$, sino que, tras la huella de su modelo, viene preñado de intención retórica, como intentaremos demostrar en las páginas que siguen.

En Ovidio, el alegato de Áyax se abre con una indignada invocación a Júpiter seguida de una maliciosa referencia a la huida de Ulises ante el adalid troyano Héctor cuando este incendiaba las naves griegas (Met. XIII 5-8); inmediatamente, se formula la que podríamos denominar propositio del discurso (vv. 9-12) ${ }^{19}$ :

tutius est igitur fictis contendere verbis, quam pugnare manu. sed nec mihi dicere promptum, nec facere est isti, quantumque ego Marte feroci inque acie valeo, tantum valet iste loquendo.

El argumento fundamental del Telamonio estriba en oponer sus propios hechos de armas a la palabrería de Ulises: facta, non verba ${ }^{20}$. Igualmente se plantea en Acuña, tras el apóstrofe a Júpiter y el recuerdo del incendio de las naves (vv. 45-53), la idea principal del discurso de Áyax (vv. 54-62):

\footnotetext{
${ }^{15}$ Cfr. W. B. Stanford, Cit., págs. 139, 141-142; F. Cupaiuolo, Itinerario della poesia latina nel I secolo dell'Impero, Napoli, Libreria Scientifica Editrice, 1973, págs. 57 y sigs.; N. Hopkinson, ed., Ovid, Metamorphoses. Book XIII, Cambridge, Cambridge University Press, 2000, págs. 15-20.

${ }^{16}$ El primero en advertir esta supuesta simpatía del poeta español por Ulises fue J. M. de Cossío, Fábulas mitológicas en España, Madrid, Espasa Calpe, 1952, págs. 189-190. La idea de que Acuña se propuso hacer del de Ítaca la «encarnación de su ideal de soldado», se debe originalmente a Mateo Mateo, cit., pág. 94, y fue desarrollada después por Rubio Árquez.

17 Cfr. Mateo Mateo, cit., pág. 98-99.

18 Rubio Árquez, cit., pág. 402.

19 «Más seguro es, así pues, con fingidas palabras contender / que luchar con la mano, pero ni para mí el hablar es fácil, / ni actuar es para éste, y cuanto yo en el Marte feroz / y en la formación valgo, tanto vale este hablando». La traducción que adoptaremos de aquí en adelante es la de A. Pérez Vega. Metamorfosis / Ovidio [en línea]. [Alicante]: Biblioteca Virtual Miguel de Cervantes, 2002. <http://www.cervantesvirtual.com/FichaObra.html?portal=0\&Ref=8286>. [Consulta: 5 sept. 2008].

${ }^{20}$ Cfr. Stanford, cit., pág. 139.
} 


\begin{abstract}
Pero más fácilmente se sustenta con fingido hablar una contienda que con armada mano una batalla, y tanto me es a mí dificultoso el decir con el arte que este dice, como a él el hacer lo que yo hago: porque cuanto yo valgo en los peligros y en los grandes efetos de la guerra tanto presume de valer hablando.
\end{abstract}

Hechos y no palabras. El poeta español traduce casi literalmente el texto del romano, pero añade inmediatamente una apostilla de propia minerva (vv. 63-64):

sin medir la distancia y largo trecho que hay desde sus palabras a mis obras.

Este mismo procedimiento amplificador se repite en seguida, a la hora de enfatizar la distinción entre lo efectivamente visto y lo narrado. Ovidio había escrito (vv. 13-14) $)^{21}$ :

nec memoranda tamen vobis mea facta, Pelasgi, esse reor, vidistis enim; sua narret Ulixes

Y traduce fielmente Acuña (vv. 65-67):

No pienso, oh griegos, que convenga agora recontaros mis hechos, pues los vistes; cuente el facundo Ulises sus hazañas

Pero remacha (vv. 68-70):

que, por facundamente que las cuente, veréis en ellas la verdad envuelta entre dos mil ficiones que la encubren.

Los siguientes cinco versos de Acuña (71-75) son amplificación del v. 15 de Ovidio (quae sine teste gerit, quorum nox conscia sola est ${ }^{22}$ ):

Ya de los casos donde él más se alaba en ninguno jamás hubo testigos

\footnotetext{
21 «Y tampoco que de recordar se hayan a vosotros mis hechos, Pelasgos, / opino: pues los visteis. Los suyos narre Ulises».

22 «esos que sin testigo hace, de los que la noche cómplice sola es».
} 
sino sola la noche y sus tinieblas, porque la claridad nunca acompaña tal hombre, tales obras ni tal vida.

A partir de aquí, Acuña sigue de cerca la pauta ovidiana a lo largo de cincuenta versos, hasta que decide sustituir los vv. 40-42 del libro XIII de las $\mathrm{Me}$ tamorfosi $^{23}$ por los siguientes, que inciden en el mérito de las armas del Telamonio frente a las arterías del Ítaco (vv. 127-131):

No puedo yo creer (ni ha de creerse)

que el valor y prudencia de los griegos

quiera que en tales armas tenga parte

el que nunca jamás tuvo ninguna

en cosa que con armas se hiciese.

Referiéndose de nuevo al incendio de las naves, el Áyax de Ovidio se pregunta: ubi nunc facundus Ulixes? (v. 92) ${ }^{24}$. Y el de Acuña amplifica la pregunta para volver sobre la oposición de los hechos a las palabras (vv. 229-234):
¿Dó estaba entonces el facundo Ulises?
¿Dó estaba su elocuencia, o de qué fruto
nos fueron sus razones bien compuestas?
$\mathrm{Su}$ lengua y el decir artificioso
mal nos valieran donde convenía
otro remedio que el de sus palabras.

En la versión del Sulmonense, Áyax se respondía a sí mismo con gran concisión, como si le bastara decir «yo sí que estuve, y salvé las naves» (vv. 93-94a) ${ }^{25}$ :

\section{nempe ego mille meo protexi pectore puppes,}

spem vestri reditus

Por su parte, el poeta español desarrolla la idea del «remedio» requerido, propuesta en el v. 234 (vv. 235-236):

Pues tal le di yo luego, y no encubierto sino a la vista de todos, peleando:

\footnotetext{
23 optima num sumat, quia sumere noluit ulla? / nos inhonorati et donis patruelibus orbi, / obtulimus quia nos ad prima pericula, simus? («¿Las mejores acaso ha de tomar, porque tomar no quiso ningunas: / yo deshonorado, y de los dones de mi primo huérfano, / porque me ofrecí a los primeros peligros, he de quedar?»).

24 «¿dónde ahora el elocuente Ulises?».

25 «Por supuesto yo protegí, mil, con mi pecho las popas, / la esperanza de vuestro regreso».
} 
Tras haber retomado por un momento la oposición de las hazañas de Áyax a la nocturnidad de Ulises («y no encubierto...»), sobre la que había insistido en los vv. 71-75, pasa a verter con una pequeñísima amplificación los vv. 93-94a, citados arriba (vv. 237-239):

yo resistí a los fuertes enemigos, yo defendí estas naves y, con ellas, la esperanza salvé de nuestra vuelta.

Pero ensancha notablemente el date pro tot navibus arma ovidiano (v. 94b) ${ }^{26}$, incluyendo una ingeniosa disquisición acerca del mérito debido a la cantidad de las naves salvadas del fuego y a la calidad del salvador (vv. 240-245):
Y no pueden valer las armas tanto (cuando a la cantidad deba mirarse) que mucho más no valgan tantas naves; pues si la calidad sola se estima, no le falta ninguna al que esto hizo para pedir, y aun merecer, las armas.

En las Metamorfosis, Áyax pone fin a su discurso sugiriendo que la contienda se dirima por los hechos y no por las palabras, incitando a los jueces a arrojar las armas de Aquiles a los enemigos para concedérselas después a aquel de los dos pretendientes que las rescate (vv. 120-122) ${ }^{27}$ :

denique (quid verbis opus est?) spectemur agendo.

arma viri fortis medios mittantur in hostes:

inde iubete peti et referentem ornate relatis.

De modo muy similar concluye el alegato del Telamonio en la versión de Acuña (vv. 296-304):

En fin, si ante los griegos (como es cierto)

obras han de valer más que palabras, si al bien decir el bien hacer precede, pongan las armas del famoso Aquiles a las puertas de Troya, o do se viere el escuadrón más fuerte de troyanos,

\footnotetext{
26 «dadme a cambio de tantas naves esas armas».

27 «Finalmente — porque, qué menester de palabras hay - contémplesenos actuando. / Las armas de ese hombre fuerte se lancen en mitad de los enemigos. / De allí ordenad que se busquen, y al que las devuelva ornad con ellas devueltas».
} 
y aquel que por su esfuerzo las cobrare por todos se le den, y así se acabe sin réplica ninguna esta contienda.

Nótese, empero, que el español ha sustituido la pregunta ovidiana del v. 120 (quid verbis opus est?) junto con su respuesta (spectemur agendo) por una sentencia que formula definitivamente el leit Motiv del discurso del Telamonio, expuesto en la propositio y retomado en los pasajes que venimos analizando: «obras han de valer más que palabras» (v. 297). Se verá ahora que, en los contados casos en que se aparta notablemente del texto latino, el traductor lo hace para prestar mayor locuacidad a Áyax, precisando sus razones e insertándolas en un hilo argumental coherente que, aunque torcido en la rueca de Ovidio, presenta en Acuña una consistencia igual si no mayor.

Por lo que atañe al alegato de Ulises, hallamos en él procedimientos de variación y de amplificación análogos a los que hemos estudiado hasta ahora, pero no nos parece que las siempre escasas enmiendas hechas por Acuña a su modelo obedezcan en este caso a una intención determinada. Es cierto que, como afirma Rubio Árquez ${ }^{28}$, los vv. 469-474 introducen consideraciones que no estaban en el original ${ }^{29}$ :

Pues, cuando con el cargo me enviastes de vuestro embajador al rey troyano, no hice allí este oficio solamente, sino el de capitán astuto y diestro; porque miré muy bien, entrando en Troya, los muros, los reparos y la gente.

Pero colegir de aquí que Acuña pretende hacer de Ulises un capitán u hombre de armas ideal, tan sagaz como valiente, parece un tanto excesivo, máxime si se tiene en cuenta que los otros dos pasajes aducidos por Rubio Árquez ${ }^{30}$ no son tan originales como él afirma. El primero de ellos habla, es cierto, de las habilidades que el propio Ulises se atribuye como militar de ingenio frente a la fuerza bruta de Áyax, a quien, en los vv. 505-506, acaba de afearle que «no sabe / (fuera de pelear) cosa ninguna» (vv. 507-518):

que si a mí me preguntan en qué entiendo, diré que busco formas para el daño

${ }^{28}$ Cit., pág. 403.

${ }^{29}$ Cfr. Ovidio, Met. XIII 196-197: Mittor et Iliacas audax orator ad arces, / visaque et intrata est altae mihi curia Troiae... («Se me envía también, audaz orador, de Ilión a los recintos. / Vista y hollada fue por mí la curia de la alta Troya»).

${ }^{30}$ Cit., págs. 403-404. 
de nuestros enemigos, y que cerco de fosos y reparos nuestro campo; que consuelo y esfuerzo a los soldados, para que con buen ánimo y alegre sufran la luenga guerra y sus trabajos; doy orden cómo el campo se provea de vitualla y armas, y de cuanto al vivir y a la guerra es necesario; voy con gran diligencia a cuanto cumple, y a todo también cumple que yo vaya.

Pero tanto estos versos como los precedentes y siguientes, exceptuando el retruécano con el que el 518 desarrolla la idea enunciada en el 517, reflejan muy de cerca el original ovidiano ${ }^{31}$. Y otro tanto ocurre con los vv. 796-803:

No quiero yo negarte que no sea provechosa tu espada en la batalla, pero tu corto ingenio ha de regirse por mi moderación y mi gobierno: tú ejercitas las fuerzas, mas no sabes ejercitallas con ningún juicio, y yo con él proveo en lo presente y prevengo así mesmo a lo futuro

Reproduce aquí Acuña sin variación sustancial el paso de Ovidio (vv. $361 b-363)^{32}$ :

tibi dextera bello

utilis, ingenium est, quod eget moderamine nostro; tu vires sine mente geris, mihi cura futuri

En pro de la interpretación de Rubio Árquez podría esgrimirse que, mientras que Ovidio había repartido fuerza e ingenio, adjudicándolos respectivamente a Áyax y a Ulises (tu tantum corpore prodes, / nos animo, vv. 365b-366a) ${ }^{33}$, prefiere Acuña reunir ambas cualidades en el de Ítaca (vv. 808-811):

31 Cfr. Ovidio, Met. XIII 211b-215: nam si mea facta requiris, / hostibus insidior, fossa munimina cingo, / consolor socios, ut longi taedia belli / mente ferant placida, doceo, quo simus alendi / armandique modo, mittor, quo postulat usus («Pues si mis hechos requieres, / a los enemigos insidio, con una fosa sus baluartes ciño, / conforto a los aliados para que los hastíos de esa larga guerra / con mente lleven plácida, enseño de qué modo hemos de alimentarnos / y de armarnos, se me envía adonde postula la utilidad»).

32 «La diestra tuya para la guerra / útil; tu ingenio es cual necesita del gobierno nuestro. / Tú tus fuerzas sin pensamiento conduces, cuidado mío es el de lo futuro».

33 «Tú sólo con tu cuerpo eres útil, / nos con el ánimo». 
tú con el cuerpo solamente vales, yo valgo con el ánimo y el cuerpo; tú tienes sola fuerza con el uno, yo el consejo y la fuerza con entrambos.

En efecto, el poeta español parece rebatir aquí la preferencia otorgada al talento por el Ulises ovidiano en un par de versos no traducidos (nec non in corpore nostro / pectora sunt potiora manu: vigor omnis in illis, 368b-369) ${ }^{34}$, equilibrando la balanza a favor de un Ulises que participa tanto de la facultad deliberativa como del arrojo marcial ${ }^{35}$. Extraña sin embargo que Acuña, en el supuesto de que fuera su intención caracterizar a Ulises como capitán completo, haya desperdiciado la ocasión que el texto latino le ofrecía para invertir a favor del Ítaco la oposición entre palabras y hechos planteada por el Telamonio. En las Metamorfosis, el primero mostraba a los jueces las heridas de su pecho para probar que no todo en él era palabrería (vv. 262b-264a) ${ }^{36 .}$

sunt et mihi vulnera, cives,

ipso pulchra loco: nec vanis credite verbis.

adspicite en!

El de Ítaca replicaba de este modo a Áyax, haciendo recaer sobre él la acusación de muñidor de palabras fingidas que este le había dirigido al comienzo de su alegato (tutius est igitur fictis contendere verbis, v. 9) ${ }^{37}$. Por su parte, Acuña omite el segundo hemistiquio del verso 263 al traducir el paso, con lo que priva a su Ulises de la posibilidad de devolverle a Áyax la acusación de mentiroso al tiempo que reivindica su propio mérito como hombre de hechos (vv. 609-611a):

Desto hay claras señales, pues que tengo en honrado lugar tantas heridas; quien lo duda las mire

Las modificaciones e incrementos hechos por don Hernando a los discursos de ambos contendientes no nos parecen, en fin, los suficientemente relevantes como para atribuir al traductor español una resuelta preferencia por Ulises que, recordémoslo, no hallamos tampoco en Ovidio. Nos resulta, asimismo, difícil

\footnotetext{
${ }^{34}$ «Y no poco en mi cuerpo / mi pecho es más poderoso que mi mano: mi vigor todo está en él».

${ }^{35}$ Cfr. Mateo Mateo, cit., pág. 93.

36 «Tengo también yo heridas, ciudadanos, / por su mismo lugar bellas. Y no creáis, vanas, mis palabras. / Contemplad aquí».

${ }^{37}$ Cfr. Bömer, cit., pág. 267.
} 
de aceptar la interpretación de Mateo Mateo según la cual nuestro poeta se sirve finalmente de la voz del narrador para «emitir su propio dictamen» en el litigio (vv. 854-861) $)^{38}$ :

No fue acabada la oración de Ulises,
cuando los capitanes (que por ella
fueron movidos, sin quedar ninguno)
unánimes pronuncian por sentencia
que se le debe a Ulises justamente
el honor y las armas que pretende:
manifiesta señal y clara muestra
de cuanto la elocuencia puede y vale.

Es, sí, evidente que el traductor añade la referencia a la unanimidad y a la justicia de los capitanes que otorgan las armas a Ulises (vv. 857-858), amplifi-

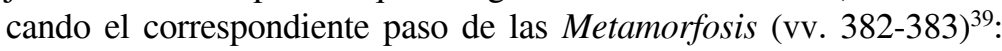

Mota manus procerum est, et quid facundia posset, re patuit, fortisque viri tulit arma disertus.

No obstante, el «justamente» del v. 868 forma parte de las palabras con que los jueces comunican su sentencia, y no expresa por tanto un juicio de valor del narrador. Además, la fidelidad a Ovidio a la hora de subrayar la habilidad suasoria que ha hecho mella en los jueces («movidos» 856, mota 382), presentando el desenlace de la lid como prueba o exemplum de la eficacia de la elocuencia («cuanto la elocuencia puede» 861, quid facundia posset 383), nos lleva e concluir que Acuña, lejos de pronunciar su propio veredicto, reproduce en lo sustancial el ambiguo comentario del Sulmonense: «mucho puede la elocuencia» ${ }^{40}$.

Mediante la confrontación del poema de Acuña con su modelo latino, esperamos haber demostrado que las variaciones y amplificaciones son, a fuer de escasas, poco significativas, y que, en consecuencia, no debemos basarnos en ellas para atribuir al traductor una intención innovadora consciente, como si obrase con el propósito deliberado de adaptar a la realidad contemporánea el sentido original del armorum iudicium ovidiano. Desde luego, estamos de

\footnotetext{
38 Mateo Mateo, cit., pág. 76.

39 «Conmovido ese puñado de próceres quedó, y, de qué la elocuencia fuera capaz, / con la situación se hizo patente, y del fuerte varón llevó las armas el diserto».

40 Más que una preferencia definitiva por Ulises (cfr. Stanford, cit., pág. 139; Bömer, cit., pág. 294), hallamos aquí una confirmación práctica del aforismo formulado ya por el sofista Gorgias, uno de los iniciadores del arte retórica, en su Encomio de Helena (frag. 11 Diels-Kranz):

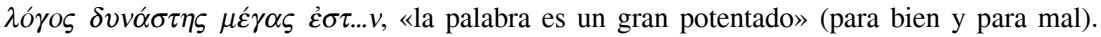


acuerdo con Rubio Árquez cuando afirma que la imitatio renacentista está llamada a rescatar «un mensaje que, insertado en un contexto diferente a aquel en el que fue lanzado, obraría en consecuencia ${ }^{4}{ }^{4}$. Es indudable que el sentido de un mensaje varía en función del contexto en que se exprese, y aun estamos dispuestos a admitir que, en el caso que nos ocupa, el contexto puede haber influido en la elección del mensaje antiguo que se pretende rescatar; es posible que, de todas las fábulas contenidas en las Metamorfosis, don Hernando se haya fijado en la Contienda por mor de su calidad de poeta-soldado, imbuido de las ideas alumbradas por su tiempo acerca del modo de compaginar ambos menesteres ${ }^{42}$. Con todo, no estamos seguros de que merezca la pena demorarse demasiado discutiendo si subyace al poema la introducción en España del debate de las armas y las letras ${ }^{43}$, o la confrontación didáctica de la fuerza con la inteligencia en «una auténtica lección sobre la esencia de la carrera militar y sus valores fundamentales $»^{44}$, o la recontextualización de una fábula que, desvirtuada por la Edad Media, devendría ahora receptáculo de las ideas renacentistas acerca del cortesano ideal, pertrechado tanto de fortaleza como de ingenio ${ }^{45}$. A la Contienda de Acuña subyace fundamentalmente, como hemos intentado demostrar, el armorum iudicium de Ovidio. Acierta Mateo Mateo al reconocer que no hay aquí ni rastro de la interpretación alegórico-moralizante a la que venía siendo sometida desde el Medioevo la poesía mitológica del Sulmonense ${ }^{46}$; no se ha ligado aquí el mito a la situación subjetiva del poeta a través de la función ejemplarizante que la Fábula de Narciso toma de su modelo italiano ${ }^{47}$, y que se explota con irónica maestría en otras fábulas de asunto ovidiano (que no «traducciones» de Ovidio) compuestas en el círculo granadino, como son las de Luis Barahona de Soto ${ }^{48}$. Lo que más llama la atención del poema que nos ocupa es la voluntad de fidelidad al original latino, que ya un primer cotejo revela; Acuña quiso poner el texto de Ovidio en verso castellano

${ }^{41}$ Cit., pág. 402.

${ }^{42}$ No debe descartarse tampoco que una cierta afición de Acuña a la poesía dialéctica, rastreable en el resto de su obra, haya hecho particularmente atractivo a sus ojos este ejercicio ovidiano de controversia retórica. La idea a sido hábilmente sugerida por G. Morelli, Hernando de Acuña. Un petrarchista dell'epoca imperiale, Parma, Università degli Studi di Parma-Studium Parmense Editrice, 1976, págs. 185-186.

${ }^{43}$ Cfr. J. M. de Cossío, cit., pág. 189.

${ }^{44}$ Mateo Mateo, cit., pág. 75; cfr. págs. 93-94.

${ }^{45}$ Cfr. Rubio Árquez, cit., págs. 398-399, 405.

${ }^{46}$ Cit., págs. 75-76.

${ }^{47}$ Basta comparar los vv. 57-88 de la versión de Acuña con las octavas VI-IX del Narciso de Alamanni.

${ }^{48}$ Existe edición digital de A. Cruz Casado, Fábulas mitológicas / Luis Barahona de Soto [en línea]. [Alicante]: Biblioteca Virtual Miguel de Cervantes, 2003. <http://www.cervantesvirtual. com/FichaObra.html?Ref=11461>. [Consulta: 5 sept. 2008]. 
y coronó con indudable éxito su proyecto, pues, como bien dejó dicho Menéndez Pelayo, logró «una traducción muy bien hecha» ${ }^{49}$.

Reivindicar hoy la vigencia del juicio de don Marcelino tiene, en nuestra opinión, dos consecuencias. En primer lugar, pierde peso la dudosa cuestión de las fuentes secundarias: de poco le deben de haber servido a Acuña la versión en prosa de Jorge de Bustamante (Amberes, 1545) o las varias italianas que podría haber consultado ${ }^{50}$, y de menos aún otras obras precedentes traídas a colación $^{51}$, si su propósito fue, como esperamos haber demostrado con el cotejo, elaborar una traducción basada directamente en el texto latino ${ }^{52}$. En segundo lugar, nos vemos obligados a aquilatar el mérito de don Hernando, replanteando el problema no como originalidad en la imitación ${ }^{53}$ sino como fidelidad en la traducción (entendida en el sentido lato en que se venía haciendo desde los antiguos, y no con las restricciones con que lo hacemos hoy cuando hablamos de «traducción literal» ${ }^{54}$ ). Porque, a la hora de verter a Ovidio al castellano, nuestro poeta obra con conciencia de traductor, ciñéndose a criterios más o menos rigurosos que podemos rastrear en determinados lugares de su obra, y que obedecen, como se verá, a su particular posición en una disputa contemporánea que en absoluto le es ajena.

En el «Argumento» antepuesto a su traducción de Le chevalier délibérée 55 , se justifica don Hernando por haber vertido en quintillas dobles el poema caballeresco del borgoñón Olivier de la Marche ${ }^{56}$ :

Hizo se esta traducion en coplas castellanas, antes que en otro genero de verso, lo uno por ser este mas usado y conocido en nuestra España, para quien principalmente se traduxo este libro. Y lo otro porque la rima Francesa, en que el fue compuesto, es tan corta, que no pudiera traduzirse en otro mayor sin confundir en parte la traducion, comprehendiendo dos y tres estrofas en una o poniendo de nuevo tanto subiecto, que fuera en perjuicio dela obra, y assi lo traduzido va una copla por otra.

${ }^{49}$ Biblioteca de Traductores Españoles, cit. Cfr. J. P. W. Crawford, loc. cit.; G. Morelli, cit., págs. 183-185.

${ }^{50}$ Cfr. Mateo Mateo, cit., págs. 80-81; Rubio Árquez, cit., págs. 388-389.

${ }^{51}$ Cfr. Mateo Mateo, cit., págs. 81-84; Rubio Árquez, cit., págs. 389-396

52 Más interesante sería investigar cuál fue el texto de las Metamorfosis, impreso o manuscrito, que pudo haber tenido Acuña ante sus ojos.

${ }^{53}$ Mateo Mateo, cit., pág. 86.

${ }^{54}$ Cfr. L. Gamberale, Plauto secondo Pasolini, Urbino, Quattro Venti, 2006, pág. 62.

55 El Cavallero / Determinado traduzido / de lengua Francesa en Castellana por / Don Hernando de Acuña, y diri- / gido al Emperador Don Car- / los Quinto Maximo Rey / de España nuestro Señor... En Anvers en casa de Iuan Steelsio, / Año de M. D. LIII. De una edición posterior de esta obra (Barcelona, Claudio Bornat, 1565) existe una reproducción facsimilar (Toledo, Antonio Pareja, 2000).

${ }^{56}$ Fols. 9v y 10r; citado por Díaz Larios, cit., pág. 40. 
El ideal del traductor es, pues, la fidelidad al texto traducido, hasta tal punto que aun para la elección del metro castellano se tiene en cuenta el firme propósito de no alterar sustancialmente el texto francés, que debe ser reflejado «una copla por otra» ${ }^{57}$. Sabido es que la opción de Acuña no satisfizo a Jerónimo de Urrea, quien, en el «Prólogo al benigno lector» de su propia versión de El caballero determinado ${ }^{58}$, escrita en tercetos encadenados, afirma: «Por tratar el libro materia grave, lo he traduzido en verso grave, como tal historia requiere» ${ }^{59}$. La pulla pudo incluso haber merecido un contraataque de don Hernado, que habría apuntado a Urrea con su sátira $A$ un buen caballero, y mal poeta, la lira de Garcilaso contrahecha (fols. $141 \mathrm{v}-143 \mathrm{v})^{60}$. Sin embargo, es el mismo don Jerónimo quien, en el «Aviso del Autor al Letor» de su traducción del Orlando furioso ${ }^{61}$, se sitúa con respecto al texto italiano de Ariosto en una posición muy similar a la que adoptaba Acuña con respecto a La Marche ${ }^{62}$ :

... me parecio tomar trabajo de le traduzir y poner en Romance Castellano quan acertada y fielmente supe, y porque la mayor virtud de la traslacion es la fidelidad, y en esta por ventura parecerá algunos yo aver faltado comparando este libro con su original estancia por estancia, quiero aquí declarar mi intención.

En seguida pasa Urrea a exponer las causas morales y políticas que hacen buenas las modificaciones introducidas por él, pero lo que nos interesa ahora es señalar la necesidad de justificación que el traductor de Ariosto comparte con Acuña, y que es lógica consecuencia de una sumaria teoría de la traducción que entroniza la fidelidad como «mayor virtud». Con las consabidas salvedades, tanto don Hernando como don Jerónimo admiten como prueba básica de la bondad de la traducción el cotejo minucioso con su original, «una copla por

57 Desde luego, Acuña hace modificaciones muy notables, pero antes ha tenido cuidado de explicarlas en la dedicatoria a Carlos v: «Han se quitado algunas cosas delas que el Autor escrivio, por ser acaecimientos, y historias del todo ignotas a España: en cuya lengua se ha traducido. Y en lugar dellas se han puesto otras mas tratadas, y conocidas no solo de nuestra nación, mas de todo el mundo: porque delo que servían en Flandes las unas, sirvan en Español las otras» (fols. 3v y 4r; citado por Díaz Larios, cit., pág. 38.).

58 Más deudora de Acuña que de La Marche, según C. Clavería, Le chevalier délibéré de Olivier de la Marche y sus versiones españolas del siglo XVI, Zaragoza, CSIC-Institución «Fernando el Católico», 1950, págs. 152 y sigs.

59 Discuso de la vida hu- / mana, y aventuras / del Cavallero determinado, / traducido del Frances por don / Ieronimo de Urrea. / En Anvers. / En casa de Martin Nucio, / M. D. LV. Con Privilegio Imperial.

${ }^{60}$ Cfr. C. Clavería, cit., pág. 150; Díaz Larios, cit., págs. 40-41.

${ }^{61}$ Orlando Furioso / dirigido al Príncipe Don / Philipe nuestro Señor, traduzido en / Romance Castellano por don / Ieronymo de Urrea. / Imprimiose en la muy noble y leal villa de Anvers en casa de / Martin Nucio y acabose a XXV dias de Agosto. / De M. D. XLIX. años.

${ }^{62} \mathrm{El}$ texto de Urrea se cita por la reciente edición bilingüe de Cesare Segre y M. de las Nieves Muñiz, Ludovico Ariosto, Orlando furioso, I, Madrid, Cátedra, 2002, pág. 81. 
otra» el primero, «estancia por estancia» el segundo. Y es este el criterio que, en nuestra opinión, subyace a la fidelidad con que traduce Acuña a Ovidio en la Contienda, donde la elección del endecasílabo suelto podría venir dada no tanto por el empleo que de este habían hecho Garcilaso y Boscán como por la intención de reproducir de la manera más exacta posible el hexámetro latino ${ }^{63}$. En todo caso, la Contienda de Acuña resulta perfectamente confrontable con el armorum iudicium de Ovidio; y otro tanto puede decirse de la Carta de Dido a Eneas, que, dejando aparte algunas variaciones análogas a las que hemos visto en el poema que hasta ahora ha ocupado nuestra atención, se puede comparar con la séptima Heroida a razón de terceto castellano por dístico latino ${ }^{64}$.

Esta voluntad de fidelidad a los textos originales nos impide definir el diálogo de don Hernando con Ovidio en términos de emulación, pues no parece posible atribuir la labor propiamente traductora de nuestro poeta a la rivalidad literaria que, según afirma Agustín de Tejada en sus Discursos históricos de Antequera, había empujado a otros a recrear las fábulas del Sulmonense ${ }^{65}$. Acuña no pretende tanto «aventajarse» a sus modelos como ofrecer al lector español versiones cabales de estos, y ocupa así una posición intermedia entre el optimismo de quienes se afanan por superar al original y el pesimismo de quienes niegan categóricamente la posibilidad de traducir poesía. Este es el inapelable parecer del cura del Quijote, que se descubre como crítico despiadado del Orlando de Urrea durante el escrutinio de la biblioteca (capítulo VI de la Primera parte) ${ }^{66}$ :

... y aquí le perdonáramos al señor capitán que no le hubiera traído a España y hecho castellano, que le quitó mucho de su natural valor, y lo mesmo harán todos aquellos que los libros de verso quisieren volver en otra lengua,

${ }^{63}$ Cfr. Mateo Mateo, cit., págs. 96-97.

${ }^{64}$ Es asimismo notable la fidelidad con que vierte Acuña el texto del Orlando innamorato, aunque, en la parte que se editó con las Varias poesías (los tres primeros cantos más las siete primeras octavas del cuarto), aumenta sistemáticamente el número de estrofas con respecto a Boiardo. Por razón de tiempo, no hemos podido cotejar su versión de Le chevalier délibéré, pero, a juzgar por el análisis de C. Clavería, cit., págs. 80 y sigs., tampoco en este caso se apartó demasiado don Hernando del original.

65 «... como Boscán la de Ero y Leandro, y Silvestre la de Narciso y Dafnes, y Montemayor y Castillejo la de Píramo y Tisbe, y don Diego de Mendoza la de Venus y Adonis, y el licenciado Soto la de Anteón, y esta propria de Vertuno con estilo tan elegante, que lo tengo por insuperable, y fue atrevimiento entrar yo donde tal ingenio ha puesto la mano; y Francisco de Tejada, mi padre, la de Troco y Salmaces, que a ninguna destas es inferior, lo cual todos hicieron por aventajarse en ellas a Ovidio». El texto del manuscrito de Tejada lo cita F. Rodríguez Marín, Luis Barahona de Soto. Estudio biográfico, bibliográfico y crítico, Madrid, Sucesores de Rivadeneyra, 1903, pág. 175. Cfr. también la introducción a la edición digital de las fábulas de Barahona hecha por A. Cruz Casado, cit.

${ }^{66}$ F. Rico, ed., Don Quijote de la Mancha. Edición del Instituto Cervantes 1605-2005, Barcelona, Galaxia Gutenberg-Círculo de Lectores. Centro para la Edición de los Clásicos Españoles, 2005, pág. 88 . 
que, por mucho cuidado que pongan y habilidad que muestren, jamás llegarán al punto que ellos tienen en su primer nacimiento.

Por su propia naturaleza, la traducción traiciona siempre en alguna medida el texto de origen, pero poemas como la Contienda o la Carta de Dido demuestran que, a pesar de ello, se puede —o se pudo - verter a Ovidio al castellano con un grado de perfección más que aceptable. Don Hernando de Acuña no rechazaba la idea de que el paso del tiempo y el cambio de lugar hicieran necesarias ciertas alteraciones, y de hecho las llevó a cabo en El caballero determinado y en el Orlando enamorado. Sin embargo, sus versiones ovidianas prueban que, adoptando como criterio fundamental la «fidelidad», es posible reducir al mínimo el hiato que media entre el original y su secuela, hasta producir un texto nuevo que, aunque llamado siempre a acoger significados nuevos por la dinámica misma de la recepción, pueda medirse con el texto viejo en términos de equivalencia. No se trata, pues, de dejar atrás al modelo mediante la emulación ni tampoco de alterarlo sin escrúpulos o de evocarlo pálidamente, en la idea de que no hay posibilidad de realizar una versión digna de tal nombre, sino de sentarse frente el original con la convicción de que la meta ideal del traductor es reescribirlo de cerca, «estancia por estancia», «una copla por otra».

\section{BIBLIOGRAFÍA}

Acuña, Hernando de, El caballero determinado (ed. facsímil), Toledo, Antonio Pareja, 2000.

Acuña, Hernando de, El caballero determinado, Amberes, Juan Stelsio, 1553.

Acuña, Hernando de, El caballero determinado, Barcelona, Claudio Bornat, 1565.

Acuña, Hernando de, Varias poesías, Madrid, Pedro Madrigal, 1591.

Alamanni, Luigi, Opere toscane, Venecia, Herederos de Lucas Antonio Giunta, 1542.

Anderson, William Scovil, P. Ovidii Nasonis Metamorphoses, Leipzig, Teubner, 1982.

Bömer, Franz, P. Ovidius Naso, Metamorphosen. Buch XII-XIII, Heidelberg, Carl Winter-Universitätsverlag, 1982.

Clavería, Carlos, Le chevalier délibéré de Olivier de la Marche y sus versiones españolas del siglo XVI, Zaragoza, CSIC, Institución Fernando el Católico, 1950.

Cossío, José María de, Fábulas mitológicas en España, Madrid, Espasa Calpe, 1952.

Crawford, J. P. Wickersham, «Notes on the Poetry of Hernando de Acuña», Romanic Review, 7, 1916, págs. 314-327.

Cruz Casado, Antonio, ed., Fábulas mitológicas / Luis Barahona de Soto, Alicante, Biblioteca Virtual Miguel de Cervantes, 2003. [en línea: <http://www.cervantesvirtual.com/FichaObra.html? Ref=11461>] [Consulta: 5 sept. 2008].

Cupaiuolo, Fabio, Itinerario della poesia latina nel $i$ secolo dell'Impero, Napoli, Libreria Scientifica Editrice, 1973.

Díaz Larios, Luis F., ed., Hernando de Acuña. Varias poesías, Madrid, Cátedra, 1982.

Gamberale, Leopoldo, Plauto secondo Pasolini, Urbino, Quattro Venti, 2006.

Hopkinson, Neil, ed., Ovid, Metamorphoses. Book XIII, Cambridge, Cambridge University Press, 2000 . 
Mateo Mateo, Ramón, «Sobre el tema de las armas y las letras en la poesía narrativa de Hernando de Acuña», Castilla, 6-7, 1983-1984, págs. 73-100.

Menéndez Pelayo, Marcelino, Biblioteca de Traductores Españoles, Santander, Aldus, CSIC, 1952-1953.

Morelli, Gabriele, Hernando de Acuña. Un petrarchista dell'epoca imperiale, Parma, Università degli Studi di Parma-Studium Parmense Editrice, 1976.

Otis, Brooks, Ovid as an Epic Poet, Cambridge, Cambridge University Press, 1966.

Pérez Vega, Ana, tr., Metamorfosis / Ovidio, Alicante, Biblioteca Virtual Miguel de Cervantes, 2002. [en línea: $<\mathrm{http}: / /$ www.cervantesvirtual.com/FichaObra.html?portal $=0 \& R e f=8286>][$ Consulta: 5 sept. 2008].

Rico, Francisco, ed., Don Quijote de la Mancha. Edición del Instituto Cervantes 1605-2005, Barcelona, Galaxia Gutenberg-Círculo de Lectores, Centro para la Edición de los Clásicos Españoles, 2005.

Rodríguez Marín, Francisco, Luis Barahona de Soto. Estudio biográfico, bibliográfico y crítico, Madrid, Sucesores de Rivadeneyra, 1903.

Rubio Árquez, Marcial, «La contienda de Áyax Telamonio y de Ulises sobre las armas de Aquiles de Hernando de Acuña: fuentes, motivos y significación», en La espada y la pluma. Il mondo militare nella Lombardia spagnola cinquecentesca. Atti del Convegno Internazionale di Pavia, 16, 17, 18 ottobre 1997, Viareggio, Mauro Baroni, 2000, págs. 385-406.

Segre, Cesare y Muñiz, María de las Nieves, eds., Ludovico Ariosto, Orlando furioso, Madrid, Cátedra, 2002.

Stanford, William Bedell, The Ulysses Theme. A Study in the Adaptability of a Traditional Hero, Oxford, Basil Blackwell, 1954.

Urrea, Jerónimo de, Orlando furioso, Amberes, Martín Nucio, 1549.

Urrea, Jerónimo de, El caballero determinado, Amberes, Martín Nucio, 1555.

Wilkinson, Lancelot Patrick, Ovid Recalled, Cambridge, Cambridge University Press, 1955.

Fecha de recepción: 8 de julio de 2010

Fecha de aceptación: 10 de enero de 2011 